\title{
Virtual learning solutions during the COVID-19 pandemic a University Italian Ophthalmology Department Perspective
}

\author{
Leonardo Mastropasqua \\ Universita degli Studi Gabriele d'Annunzio Chieti e Pescara \\ rossella d'aloisio ( $\square$ ross.daloisio@gmail.com ) \\ Universita degli Studi Gabriele d'Annunzio Chieti e Pescara \\ Lorenza Brescia \\ Universita degli Studi Gabriele d'Annunzio Chieti e Pescara \\ Lisa Toto \\ Universita degli Studi Gabriele d'Annunzio Chieti e Pescara \\ Rodolfo Mastropasqua \\ University of Modena and Reggio Emilia \\ Luca Agnifili \\ Universita degli Studi Gabriele d'Annunzio Chieti e Pescara
}

\section{Research article}

Keywords: e-learning, virtual learning, Student, Residents, University, Ophthalmology department, COVID-19 pandemic

Posted Date: June 17th, 2020

DOI: https://doi.org/10.21203/rs.3.rs-35088/v1

License: (c) (i) This work is licensed under a Creative Commons Attribution 4.0 International License. Read Full License 


\section{Abstract \\ Background}

Few months after the COVID-19 pandemic burst, many aspects of the human life, including education, dramatically changed. Because of the lockdown measures taken to limit the virus spread in Italy, in-person teaching and learning have been interrupted in all health care disciplines and readapted in virtual formulae.

\section{Methods}

As an academic ophthalmology department, we had to maintain the educational needs of medical and orthoptic students, internships, surgical training of residents, as well as to cover the scientific update of health care personnel (HCPs), and the continuation of research and academic activities. To assure these needs we ideated an educational strategy and a team, which was then translated on a multichannel virtual platform created with Microsoft Teams.

\section{Results}

In this platform there were twenty-one channels organized in a public view mode, open to all Team members, or in private view mode to separate non-permanent HCPs, internships, residents, and students' tasks, from permanent HCPs tasks. Virtual channels were dedicated to provide theoretical lessons, clinical cases, surgical video, internal meetings and webinar, to offer news from scientific societies, requests of appointments from biomedical companies, links with ophthalmological websites, to move forward research projects, to participate at institutional academic duties, and to obtain feedbacks from users. Residents continued their training on surgery using a surgical simulator, after consulting an agenda uploaded into the dedicated virtual channel.

\section{Conclusions}

These positive initial results should represent a boost to rapidly proceed with the development of even more versatile virtual learning solutions, given that the forecasts for the duration of the COVID-19 pandemic are not encouraging.

\section{Background}

Four months after the burst of the novel coronavirus disease (COVID-19) outbreak, many fields of the human living, ranging from health care, work, home and social living, economy, on-line activities, to teaching and learning dramatically changed. Undoubtedly, the education disruption represents one the most glaring change induced by the COVID-19 pandemic.

Because of the lockdown measures taken to limit the virus spread, which still forces more than a third of the global population to stay home, schools and universities were closed and learning strategies have been readapted from inperson to the distance formulae. In response to these restrictive measures, UNESCO recommended the use of distance learning programs and open educational applications and platforms so that University and Schools can reach learners remotely and limit the disruption of education [1]. Thus, e-learning erupted worldwide, and currently represents the only available solution to satisfy learning requests in all fields of the human life, including health care. 
In an academic ophthalmology department, which is devoted to patient care, research and student's education, teaching and learning programs provide lessons and exams to students, support residents in their clinical and surgical training, offer the scientific update to the permanent health care personnel. Besides these aspects, relations with biomedical companies, the maintenance of research groups activities, and the participation to academic institutional duties, represent additional crucial moments than need to be constantly covered.

After a few weeks from the outbreak burst, all learning-related activities underwent a dramatic fall. Whether appropriate measures are not timely taken and restriction strategies will be prolonged for long-lasting periods, this may lead to a potential high negative impact on the education of the next generation of health care professionals (HCPs). Because of this, given that forecasts for duration of the Covid-19 pandemic are not encouraging until effective medications and/or vaccines will be available, possible strategies to limit the impact of restrictive measures on teaching, learning, and research activities are under evaluation in all fields of health care. The aims of the present paper were to give an overview of the impact of the lockdown measures on learning activities in Ophthalmology, and to report the strategies and educational tools implemented by an Italian Ophthalmology University Department during the COVID-19 pandemic.

\section{Effects Of Covid-19 Pandemic On Learning In Italy 2.1. General effects}

From the last week of February, when the first case of Covid-19 was diagnosed in Italy, all in-person University learning activities, such as lessons, courses, exams, thesis dissertation, internships, were immediately stopped by law (Decree of the Prime Minister, 4 March 2020). Moreover, medical congresses and meetings have been also deferred to a date subsequent to the term of effectiveness of the decree. As a result, the high number of meetings monthly offered by Ophthalmology Societies or biomedical Companies had a dramatic fall in the period between 20th February and the last decade of April 2020.

\subsection{Effects on a University Ophthalmology department}

In all University hospitals throughout Italy, departments not directly involved in the essential life support to Covid-19 patients, such as those of Ophthalmology, routine clinical and surgical practices were suspended to create dedicated areas for intensive care units. Therefore, visits and surgeries were restricted to the management of urgent conditions accessing hospital through the emergency service.

Disruptive effects of these unprecedented measures reflected to the non-permanent staff of our Ophthalmology department, which is constituted by medical and orthoptic students, trainees, residents in training and ophthalmologists (observer fellows, PhD, and post-doctoral fellows, assistant professors), to whom was recommended to stay at home. In-person lessons to all categories of HCPs, as well as assistance to students preparing thesis dissertation, were suspended. Given that ophthalmology is a clinical, laser, and surgical discipline, many restrictions regarded residents in training, who limited their clinical activities to the co-management of emergency cases, whereas suspended laser and surgical training.

All pharmaceutical and biotech companies suspended the in-person information to ophthalmologists, and canceled hospital summits discussing collaboration strategies.

Internal periodic meetings reserved to permanent HCPs, that usually represent a part of the educational activities of a university ophthalmology department were suspended. 
Congress, meetings, and courses regarding all fields of ophthalmology have been progressively canceled by scientific societies or biomedical companies, until the Italian government stopped them by law (Decree of the Prime Minister, 4 March 2020). At the same time, all research activities planned within University, represented by intra- or inter-departmental meetings or seminars, and laboratories activities, were postponed until a later date.

\subsection{Effects on e-learning}

The e-learning is not a novel concept in health care. Thanks to applications for smartphone or tablet or through social media, some aspects of teaching and learning, especially those concerning organization or material sharing, frequently take place virtually. Moreover, Universities often have an e-learning section.

Nevertheless, though these tools may cover some important functions of the distance education, they lack the organization properties to permit the realization of a suitable educational platform.

More advanced platforms, represented by Microsoft Teams (Microsoft Corporation, USA), Zoom (Zoom Video Communications, San Jose, CA), Skype (Skype Technologies, Palo Alto, CA), Cisco WebEx, (Cisco Webex, Milpitas, C), Google Hangouts or Google Classroom (Microsoft Corporation, USA) can give a more powerful solution to educational needs and, thus, have been utilized from the first weeks after the outbreak burst in different medical disciplines [2, 3]. Microsoft Teams appears as one of the most flexible software capable to integrate people, content, and tools in an effective way. For the most part users are logging in from computers, but this program is also accessible from smartphones and tablets, which allows learner engagement from any location.

\section{Strategies To Maintain Learning And Research Activities In An Italian Ophthalmology Department}

In order to maintain all education and research-related activities that our Department (Ophthalmology Clinic, Center of Excellence in Ophthalmology, National Hugh-Tech Eye Center, Italian School of Robotics in Ophthalmology, University G. d'Annunzio of Chieti and Pescara, Italy) normally provides to students, trainees, non-permanent and permanent HCPs during the Covid-19 pandemic, we ideated an educational strategy through which a Team and a virtual learning platform were created by using Microsoft Teams.

\subsection{Educational strategy}

The strategy adopted to cover the educational needs and research activities was based on a main educational stream, in which the permanent academic staff re-adapted teaching systems in order to offer to all categories of students and HCPs, according to their role, online teaching, up to dates, and virtual training in a dynamic and interactive way (Fig. 1). Different virtual solutions were used to reach these purposes, which were realized by creating a team and in a virtual learning platform, through the institutional access of the University (G. d'Annunzio University of Chieti-Pescara) on Microsoft Teams. This team was named as "ExE' for Education and Research Team", and the logo of our Department was chosen to identify the Team (http://www.clinicaoftalmologica.it/index.php) (Fig. 2).

Users may log in from computers, smartphones or tablets, which allows learner engagement from any location.

\subsection{Virtual learning platform}

The virtual learning platform we created, was composed by twenty-one channels dedicated to cover all educational, academic, and research aspects of our Department. Team channels have been organized in a public view mode, 
open to all Team members, or in private view mode (padlock logo) in order to distinguish between non-permanent HCPs, internships, residents, and students, and permanent HCPs dedicated sections.

\subsubsection{Educational programs for students and internships}

The teaching programs dedicated to the three categories of students (medical, orthoptic and grad) and for internships were re-planned moving from the traditional in-person to the distance didactics; to activate this learning modality, the academic staff personnel adapted or produced new PowerPoint presentations for an online use, and gave their lectures according to a pre-defined weekly schedule. At the end of the lecture, the academic staff given presentations available for a later review in remote manner and for the download (Lessons for Internship, Medical Students, and Students in Orthoptics channels). Some lessons dedicated for students in Orthoptics, especially those given by other non-ophthalmological academic teachers, were given available on the e-learning section of the University (UdA e-Learning channel; https://elearning.unich.it). A dedicated channel to ensure graduation students needing assistance for the preparation of their thesis was also created (Grad Students channel).

Our strategy was based mainly on "collaborative learning", which is a relatively new concept of teaching consisting of individual learning as a result of collective collaboration, with the teacher acting as moderator of the discussion; this strategy enhances learning by working together. Lessons started with a brain storming, useful to collect ideas focusing on a single theme letting students have different ideas about a topic, to solve a problem and to give solutions. Afterwards, the teacher gave its lecture on the proposed topic. The high level of interactivity, stimulated by questions proposed by the teacher during the course and at the end of the lecture, promoted an active learning with a high level of students' attention.

Finally, the Feedback from Students and Staff channe/ was provided to students to post their level of satisfaction for each lesson, and to Staff to report the level of interaction of students.

\subsubsection{Educational programs for Residents}

Theoretical lessons were weekly given by the academic staff through the Lessons for Residents channel, where PowerPoints and surgical videos were uploaded in accordance with the year of the course. As for students, presentations were given available for the download at the end of the lecture.

Clinical practice was changed in case-based learning (Clinical Cases channel), where the academic representative of each Department section (Glaucoma, Retina, Ocular Surface, Cataract and Refractive Surgery, Inflammatory Diseases, and Pediatric Ophthalmology section) prepared dedicated PowerPoint reporting virtual clinical cases, from anamnesis to therapy. Additionally, synchronous digital spaces allowing residents to meet invited guest lecturers, with live interactions, interactive whiteboard, and chats were also contemplated to promote dynamic learning (Guest Lecturers channel).

Direct links to the most important scientific Ophthalmology journals (with the Institutional free access), national or international societies that have announced the upcoming congress in the virtual modality, websites and surgical video platforms specific for ophthalmology (eLos by ESASO, EyeTube video, News from Scientific Ophthalmology Societies and Virtual Meetings channels) have been also provided.

A simulator for cataract and vitreoretinal surgery (EyeSiß - VR Magic Surgical Simulator, Mannheim, Germany) normally supplied at our Department, was given completely available to residents to continue their surgical training in a virtual modality. A daily agenda was created by the academic personnel in order to permit at one resident at 

channel Clinical Cases.

\subsubsection{Educational programs for Permanent and Non-Permanent HCPs}

In normal conditions, our Department organizes internal meetings on Friday morning to give updates to the permanent and non-permanent HCPs, by reviewing some of the most recent and important publications in each field of ophthalmology. These meetings are open to all categories of medical doctors, orthoptists, and nurses. In order to maintain this service during the Covid-19 pandemic, our virtual learning platform provided a dedicated channel in which were uploaded the pdf version of a couple of publications for sector, which were then discussed with the scientific representative (Internal meetings for HCPs channel). Since a great part of the update for medical personnel takes place through congress, meetings and courses, we tried to offer also webinars to our HCPs. Therefore, we created internal webinars, as well as provided links for specific webinars available on line, in order that HCPs (and residents) could participate to events focused on cornea and ocular surface, glaucoma, retina, vitreoretinal surgery, cataract, or refractive surgery (Webinars channel).

Finally, the contact with biomedical companies was even guaranteed. For this purpose, companies used already available virtual learning platforms (such as the Veeva CRM Engage Meeting), which permitted them to maintain communications and collaborations with our Department. Appointments with medical sales representatives and companies were scheduled within a dedicated agenda (Biomedical Companies Appointments channel).

\subsubsection{Research and Academic Activities}

Our research staff, composed by both permanent and non-permanent HCPs such full, associate, and assistant professors, or PhD students and fellows, continued their scientific work mainly in "smart working" fashion and by using Microsoft Teams to discuss and share scientific materials or to propose new projects (Research Projects and PhD Students Activities and Reports channels). The permanent academic personnel participated to the routine academic activities via reserved invitations sent by the University, following an agenda available on the academic activities channel consisting on distance learning lessons, exams in distance learning, distance learning degree sessions, department council, degree course council, consults of the presidents of degree courses, PhD activities, meetings between the rector of university and university staff.

The first distance learning session was held on March 16 at 5 PM, and was dedicated to 16 residents in attendance who, given the lockdown measures, were all at home during the conference meeting time. This first session consisted of a pre-prepared lecture-based discussion with PowerPoint slides, on post-surgical endophthalmitis. The first distance learning lessons to medical students was held on March 23 at 2 PM. The topic was cataract and consisted on pre-prepared lecture with PowerPoint slides with interactive discussion at the end. Thereafter teaching was provided according to the pre-existing university calendar. On the contrary medical students practical training activity that should have been carried out in the hospital was suspended.

Distance learning lessons for students of orthoptics and ophthalmology assistance course were provided via oral lessons using PowerPoint slides according to pre-existing calendar or modified according to students' needs. Orthoptics students practical training activity normally carried out in the Ophthalmology clinic was suspended and replaced by distance learning lessons on practical ophthalmology topics.

\section{Outcomes Reached By The Exe' For Education And Research Team}


Table 1 reports the time range of educational programs provided within virtual channels of the platform and receivers who were dedicated.

Table 1

Frequency and receivers of the educational programs and research activities provided by the ExE' for Education and Research Team.

\begin{tabular}{|c|c|c|c|c|c|c|c|}
\hline & P-HCPS & NP- & RESIDENTS & INTERNSHIPS & STUDENTS & & \\
\hline & & & & & Medical & Orthoptic & Grad \\
\hline $\begin{array}{l}\text { Theoretical } \\
\text { lessons } \\
\text { (frequency } \\
\text { and } \\
\text { cumulative } \\
\text { data) }\end{array}$ & - & - & $\begin{array}{l}2 \\
\text { hours/week }\end{array}$ & 2 hours/week & $\begin{array}{l}2 \\
\text { hours/week }\end{array}$ & $\begin{array}{l}6 \\
\text { hours/week }\end{array}$ & - \\
\hline $\begin{array}{l}\text { Clinical } \\
\text { Cases }\end{array}$ & - & - & $\begin{array}{l}3 \\
\text { cases/week }\end{array}$ & 3 cases/week & - & - & - \\
\hline $\begin{array}{l}\text { Guest } \\
\text { Lecturers }\end{array}$ & $1 /$ month & $1 /$ month & $1 /$ month & $1 /$ month & - & - & - \\
\hline $\begin{array}{l}\text { EyeTube } \\
\text { video }\end{array}$ & $\begin{array}{l}\text { Free } \\
\text { access }\end{array}$ & $\begin{array}{l}\text { Free } \\
\text { access }\end{array}$ & Free access & Free access & - & - & - \\
\hline $\begin{array}{l}\text { eLos by } \\
\text { ESASO }\end{array}$ & - & $\begin{array}{l}\text { Free } \\
\text { access* }\end{array}$ & $\begin{array}{l}\text { Free } \\
\text { access* }\end{array}$ & - & - & - & - \\
\hline $\begin{array}{l}\text { EyeSi } \\
\text { Simulator } \\
\text { Agenda }\end{array}$ & - & - & $\begin{array}{l}2 \\
\text { hours/week }\end{array}$ & - & - & - & - \\
\hline $\begin{array}{l}\text { News from } \\
\text { Scientific } \\
\text { Societies }\end{array}$ & $\begin{array}{l}\text { Free } \\
\text { access }\end{array}$ & $\begin{array}{l}\text { Free } \\
\text { access }\end{array}$ & Free access & Free access & - & - & - \\
\hline $\begin{array}{l}\text { Biomedical } \\
\text { Company } \\
\text { appointments }\end{array}$ & $\begin{array}{l}\text { Weekly, } \\
\text { upon } \\
\text { request }\end{array}$ & $\begin{array}{l}\text { Weekly, } \\
\text { upon } \\
\text { request }\end{array}$ & $\begin{array}{l}\text { Weekly, } \\
\text { upon } \\
\text { request }\end{array}$ & - & - & - & - \\
\hline Webinars (n) & 5 & 4 & - & - & - & - & - \\
\hline $\begin{array}{l}\text { Internal } \\
\text { Meetings }\end{array}$ & 1/week & 1/week & 1/week & - & - & - & - \\
\hline $\begin{array}{l}\text { Research } \\
\text { Projects }\end{array}$ & 1/week & 1/week & 1/week & - & - & $\begin{array}{l}\text { Upon } \\
\text { academic } \\
\text { staff } \\
\text { request }\end{array}$ & $\begin{array}{l}\text { Upon } \\
\text { request } \\
\text { for } \\
\text { thesis }\end{array}$ \\
\hline
\end{tabular}

From March 16 to April 30, our Team provided an educational program consisting of 14 hours of theoretical lessons to residents, 12 hours to medical students, and 36 hours to orthoptic students; clinical cases were provided only for residents and internships according to material availability. The mean time of each presentation was $69 \pm 5$ minutes, whereas was 30 minutes for clinical cases. During the period of observation, we did not have requests of assistance 
from grad students preparing their dissertation. We invited three guest key opinion leaders of other Italian

universities to provide lectures on glaucoma, retina, and ocular surface for all HCPs, residents and internships.

Each resident accessed to the surgical simulator two times a week, with a session of cataract surgery lasting 1 hour; in this way, four residents per day, with thirty minutes of interval between sessions, could have their surgical training. We had thirteen HCPs that used links uploaded within the dedicated channel to decide whether registering to upcoming virtual congress, such as that of the International Council of Ophthalmology and the Italian Ophthalmology Society. Only three ophthalmologists of the permanent HCPs staff were reached by biomedical companies, through the Veeva CRM Engage Meeting.

Internal meetings were organized by our academic staff and proposed once a week for HCPs and residents, whereas webinars were mostly promoted by biomedical companies, and were mainly dedicated on up to date on surgical procedures or interpretation of printouts of diagnostic platforms such as optical coherence tomography (OCT).

Research activities were mainly focused to carry on ongoing projects, and to organize publications on COVID-19 and ophthalmology; contacts were taken by the academic staff, through the dedicated platform channel, with HCPs, residents, internships, and orthoptic students. Overall, feedbacks were positive, in the $91.7 \%$ of cases, from students, and in $89.3 \%$ from teachers.

\section{Discussion And Conclusions}

In health care, fellows and residents of surgical specialties such as Ophthalmology are at risk to experience the highest negative impact of the COVID-19 pandemic restrictive measures because surgical training programs, as well as theoretical learning, may be deeply altered. In support of this, a recent study reported that the $85.2 \%$ of Italian urology residents, who have an important surgical activity, had their surgical training fully compromised [4]. In order to remedy to this situation and continue the educational program of the year, university departments implemented digital learning strategies for students, fellows and residents.

At the Harvard Medical School of Boston in USA, cardiologists utilized a combination of Zoom and Microsoft Teams platforms to continue educational activities during COVID-19 pandemic, with positive feedback from both fellows and students [2]. In line with these results, we decided to use Microsoft Teams to create an educational and research team, with more than twenty virtual spaces (channels), obtaining excellent results in terms of teacher and student satisfaction.

In a general judgment, we found that our implemented strategies were successful since permitted to smartly and interactively discuss theoretical topics, clinical cases, surgical video, or recent publications, frequently in a surprising deeper way compared to standard conditions. In detail, our platform proved valuable for the high versatility and easy-to-use nature, and for the chance to have in a single application several digital spaces covering all aspects of education and research demanded to a university department of Ophthalmology.

As adopted in the teaching method of the Brooke Army Medical Center (San Antonio, Texas, USA) during this period, we found that providing students with prerecorded digital material before lessons or tele-conferences, or watching video lectures at any time in remote manner, were useful ways for improving knowledge of a topic [5]. This American institution described also the utility to differentiate juniors from seniors' residents in two tracks, based on the appropriate level, in order to have a more homogeneous classroom [5]. To comply with this strategy, we organized separate channels for each typology of students and for residents. 
Similar solutions were adopted in a Singapore department, in order to ensure a high-quality medical education to residents and students of the Medicine faculty $[6,7]$. In this department clinical rotations for undergraduates and training for residents were immediately stopped, while virtual lectures and teleconferences were scheduled. Video conferences and webinars were given available to show and teach surgical techniques for residents of surgical specialties, even though individual learning was encouraged [7]. Differently, we observed that collaborative and dynamic teaching was more appreciated than the individual learning, with students showing a high level of communication with academic staff to solve clinical problems. Concerning surgical training, our residents had the possibility to daily access to the surgical simulator, after consulting the dedicated channel of the platform where was uploaded a dedicated weekly agenda, and in accordance with their tutors. This appeared a very good strategy since, as stated by an Editorial of the American Academy of Ophthalmology, the availability of a surgical simulator platform adopting simulation technology with feedback provided by the system, allows for an objective and structured training to a high level of skill [7].

When working in a virtual learning platform, the choice of the communication method and skills of the teachers are crucial to reduce the gap between students and teachers: in this optic, many interactions should be promoted by the active role of the moderator, to avoid a low interest and a low participation of the audience. In fact, it has been observed a direct positive correlation between the number of students' contribution to the online discussion and their final rating of the session during online anatomy lessons [8]. In our experience we calculated that each lesson lasted almost $10-20 \%$ more than standard in-person lectures, which in our department is normally less than 1 hour per session; this results showed an evident interest and interactivity of the audience.

Our system proved valuable also to share key news to HCPs, such as scientific societies guidelines related to the COVID-19 pandemic, or announcements of upcoming virtual congress, where the staff had the possibility to directly register. Finally, the virtual system permitted our academic staff to keep in touch with other intra-university departments, other universities, and with residents or students, in order to carry on ongoing research projects.

Nevertheless, our virtual learning platform presented different limitations. First, faculty may struggle with the novel technology in case of poor ability with the use of computers, and students may have problems in case of poor domestic bandwidth connections. Second, distance learning may expose to the risk of student inattention during session, especially in absence of a direct video-camera control. Finally, the system must be tested with longer followup, in order to assess whether the level of satisfaction of teachers and students remains high during time.

In summary, the COVID-19 pandemic induced a dramatic disruption of all aspects of education in ophthalmology, with the need of a rapid re-organization of learning strategies. We responded to this situation by implementing a virtual learning platform, provided by a multi-channel architecture that permitted to continue offering various levels of education to HCPs, residents and students, as well as to carry on research activities and academic duties. This strategy, even after a short follow-up, proved valuable with a high level of appreciation reported by all categories of team members. Given that e-learning will progressively grow and spread in the next months, more implementations of technologies with novel strategies are urgently needed to overcome all COVID-19-related educational issues.

\section{Abbreviations}

HCPs Health Care Professionals

OCT Optical Coherence Tomography 


\section{Declarations}

\section{Ethics approval and consent to participate}

Not applicable.

\section{Consent for publication}

Not applicable.

\section{Availability of data and materials \\ Data are available from the authors upon reasonable request. \\ Competing interests}

The authors declare that they have no competing interests.

\section{Funding}

None.

\section{Authors' contributions}

LM, RDA, LA and LT made substantial contributions to the conception and design of the study, and the analysis and interpretation of data. LB and RM contributed to the analysis and interpretation of data. RDA and LT drafted the work; LM, RDA, LA, LT and RM contributed to the final approval of the version to be published. All authors approved the final manuscript for publication and have agreed to be accountable for all aspects of the work.

\section{Acknowledgements}

Not applicable.

\section{References}

1. "290 million students out of school due to COVID-19. UNESCO releases first global numbers and mobilizes response". UNESCO. 4 March 2020. Retrieved 6 March 2020. Link available at: https://en.unesco.org/news/290million-students-out-school-due-covid-19-unesco-releases-first-global-numbers-and-mobilizes.

2. Almarzooq Z, Lopes M, Kochar A. Virtual Learning during the COVID-19 Pandemic: A Disruptive Technology in Graduate Medical Education (2020). J Am Coll Cardiol. doi:10.1016/j.jacc.2020.04.015.

3. Evans DJR, Bay BH, Wilson TD, Smith CF, Lachman N, Pawlina W. Going Virtual to Support Anatomy Education: A STOP GAP in the Midst of the Covid-19 Pandemic. Anat Sci Educ. 2020. doi:10.1002/ase.1963.

4. Amparore D, Claps F, Cacciamani GE, et al (2020). Impact of the COVID-19 pandemic on Urology Residency Training in Italy. Minerva Urologica e Nefrologica. 
5. Chick RC, Clifton GT, Peace KM, et al. Using Technology to Maintain the Education of Residents During the COVID-19 Pandemic. Surg Educ. 2020. doi:10.1016/j.jsurg.2020.03.018.

6. Liang ZC, Ooi SBS, Wang W. Pandemics and Their Impact on Medical Training: Lessons From Singapore. Acad Med. 2020. doi:10.1097/ACM.0000000000003441.

7. McCannel CA. Simulation Surgical Teaching in Ophthalmology (2015). Ophthalmology;122:2371-2.

8. Stone DM, Barry DS. Improving Virtual Learning Interactions: Reducing the Transactional Distance of Online Anatomy Modules (2019). Anat Sci Educ;12:686-687.

\section{Figures}

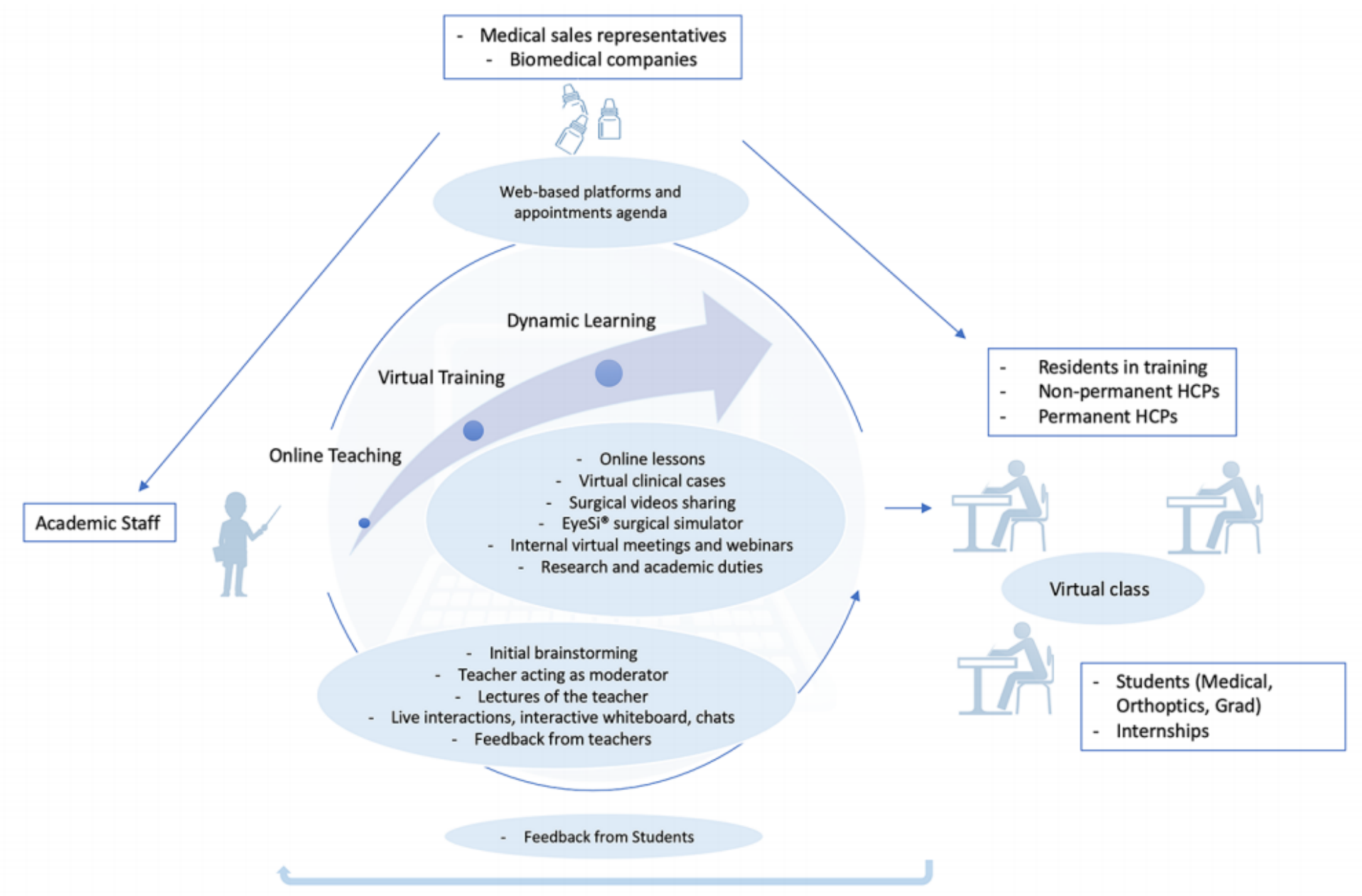

Figure 1

Main educational stream adopted to cover the educational needs, and research and academic activities. 


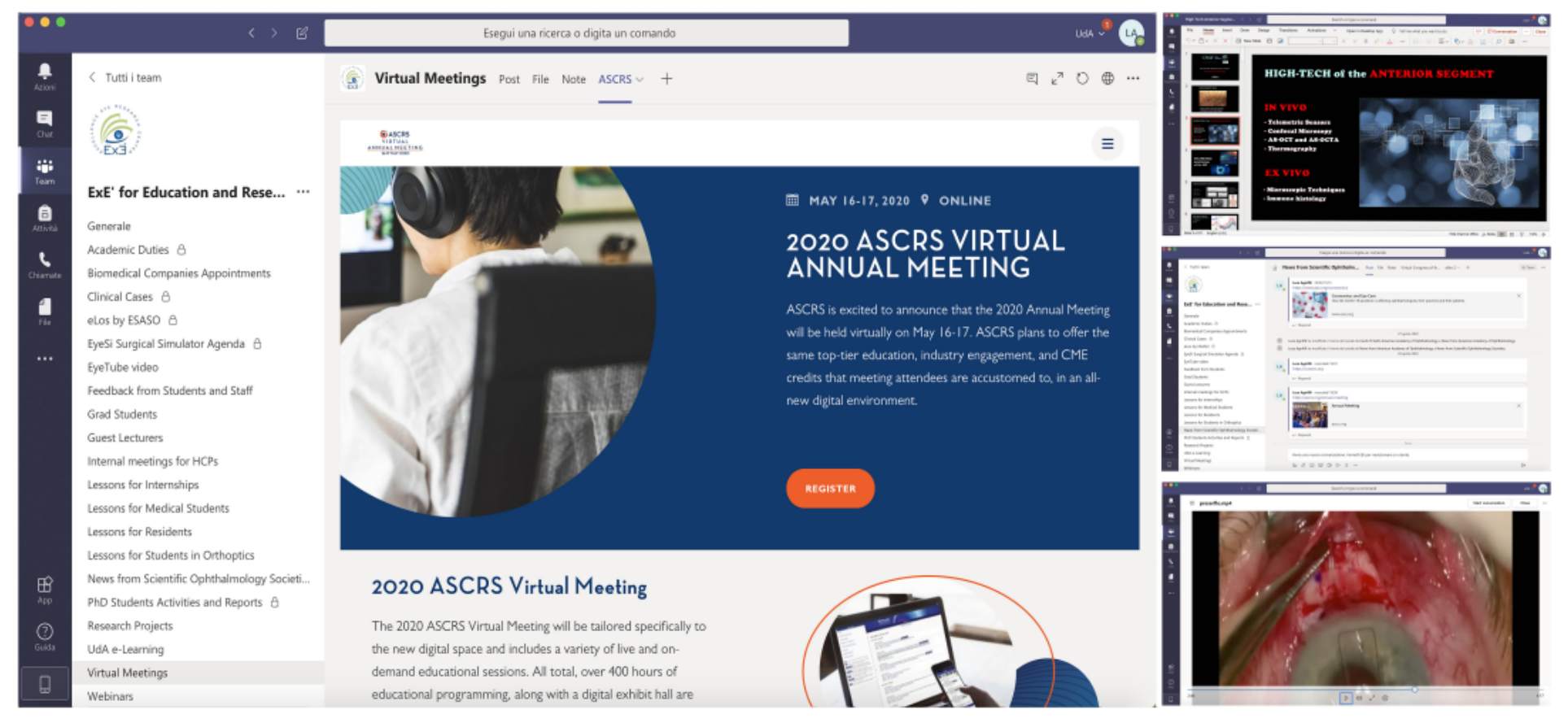

\section{Figure 2}

Mosaic of Microsoft Teams' screenshots of four channels contained in the ExE' for Education and Research Team platform. The left side of the figure shows an example of the link provided to register to the upcoming American Society of Cataract and Refractive Surgery Society (ASCRS) virtual congress. On the right side three additional channels of the platform are reported. Upper right: example of a PowerPoint slide from a glaucoma lecture, uploaded into the virtual channel "lessons for residents"; mid right: link provided to connect to some ophthalmology societies such as American Academy of Ophthalmology (AAO), ASCRS, and International Council of Ophthalmology (ICO), located in the virtual channel "news from scientific ophthalmology societies"; bottom right: video on a surgical procedure for glaucoma uploaded into the virtual channel "clinical cases". 